\title{
Negocio inmobiliario y condicionantes para el desarrollo competitivo sustentable en San Martin de los Andes y Villa La Angostura, Neuquén
}

\section{Real estate Business and constraints to sustainable competitive development in San Martín de los Andes and Villa La Angostura, Neuquén}

\author{
Rodrigo González Burgos \\ Centro de Estudios para la Planificación y el Desarrollo Turístico Sustentable (CEPLADES \\ Turismo); Universidad Nacional de Comahue, Argentina. \\ rodrigogonzalezburgos@gmail.com
}

ARTÍCULO

Recibido: mayo de 2017

Aceptado: julio de 2017

\begin{abstract}
Resumen
El presente artículo indaga sobre los efectos regresivos que el negocio inmobiliario promueve en el desarrollo de San Martín de los Andes y Villa La Angostura. El estudio parte de la observación de ciertas condiciones de desarrollo que experimentan estos destinos turísticos de montaña y que pueden interpretarse como una de las derivaciones más críticas de las movilidades del post turismo. El denominador común en estos destinos es el incremento creciente y sostenido de la oferta turística, siempre por encima del crecimiento de la demanda. El negocio inmobiliario, operando en la "sombra del turismo", ha contribuido a esta situación que pone en jaque la dimensión económica de la competitividad sustentable de estos destinos. El trabajo forma parte de la investigación de la tesis de Doctorado Migraciones de amenidad y desarrollo competitivo sustentable de los destinos turísticos de montaña de la Patagonia Norte, Argentina, del Departamento de Geografía de la Universidad Nacional del Sur.
\end{abstract}

Palabras claves: Post turismo; destinos turísticos de montaña; negocio inmobiliario; sombra del turismo.

\begin{abstract}
The article explores the regressive effects of real estate business developed in Villa La Angostura and San Martín de los Andes. The study starts from the observation of certain conditions of development that these mountain tourist destinations, and which can be interpreted as one of the most critical derivations of post tourism mobilities. The common denominator in these destinations is the sustained and increasing tourism supply, always above the growth of demand. The real estate business, operating in the "shadow of tourism" has contributed to this situation, which puts in check the economic dimension of the sustainable competitiveness of these mountain tourist destinations. This work is part of there search of the doctorate thes is "Amenity migrations and sustainable competitive development of mountain tourist destinations of Northern Patagonia"; Argentina, in the Department of Geography, Universidad Nacional del Sur.
\end{abstract}

Keywords: Post tourism; mountain tourism destinations; real estate business, shadow of tourism. 


\section{A modo de introducción}

A partir de la observación realizada en Villa La Angostura y San Martín de los Andes, se puede plantear como punto de partida ciertas condiciones de desarrollo que pueden interpretarse como una de las derivaciones más críticas de las movilidades del post turismo. El denominador común en estos destinos de montaña es el incremento creciente y sostenido de la oferta turística, siempre por encima del crecimiento de la demanda. El negocio inmobiliario, operando en la "sombra del turismo" (Otero y González, 2012) ha contribuido a esta situación, que pone en jaque la dimensión económica de su competitividad sustentable.

El post turismo se define en un sentido amplio como un proceso de transición residencial y reconversión de los destinos turísticos. Este enfoque incluye nuevas estrategias residenciales de la población activa y retirada, que en la forma de migrantes de amenidad, llegan a estas localidades turísticas para recrear una "nueva vida", buscando un medio ambiente, una calidad de vida imaginada y una sociabilidad de la vida de vacaciones como parte integral de la vida cotidiana (Bourdieu, 2008).

Las migraciones de amenidad conforman una tendencia social a escala mundial, que puede describirse como la migración de personas desde las grandes metrópolis a ciudades pequeñas o pueblos en el interior, sobre todo localidades de montaña, cuya calidad ambiental y cultural es percibida como superior a la de sus antiguos lugares de residencia. Dicha migración se considera un "agente de cambio global que tiene especial efecto en los parajes rurales o pueblos más pequeños" (Glorioso y Moss, 2006, p. 83). Este fenómeno es una migración inversa, de la ciudad al campo; los sujetos de este proceso son generalmente personas que, habiendo sido previamente turistas, deciden regresar a ciertos lugares, no para visitarlos, sino para constituirse en habitantes de los mismos (Nakayama y Marioni, 2007).

Los destinos turísticos de montaña son lugares elegidos por migrantes de amenidad en todo el mundo. Son espacios con significados y asociaciones propias, para sus residentes e incluso para sus visitantes, pero también poseedores de una combinación de características que lo definen como bellos paisajísticamente, cosmopolitas, exóticos, aunque también degradados social y ambientalmente. Las migraciones de amenidad pueden considerarse en muchos casos como una sombra del turismo (González, Otero, Nakayama, Marioni, 2009; Otero y González, 2012), ya que el tipo de movilidades que causan podrían interpretarse como regresivas en términos de desarrollo local. En el Corredor de los Lagos, y particularmente en destinos turísticos de montaña como Villa La Angostura y San Martín de los Andes, se observan problemas relacionados con la competitividad sustentable a partir de los procesos de 
migración de amenidad. En los últimos veinte años, estas migraciones atrajeron inversiones orientadas a la construcción de emprendimientos hoteleros que hoy no son rentables, con baja generación de empleo por tratarse en su mayoría de empresas familiares y con demanda estacional. El resultado fue la creación de una burbuja de crecimiento exógeno que favoreció el desarrollo de una economía inmobiliaria en estos destinos turísticos de montaña.

Así, la investigación indaga en la relación entre el negocio inmobiliario y la crisis de rentabilidad en estos destinos turísticos de montaña debido al sobre aumento de la oferta hotelera y extra hotelera; crisis que pone en jaque la dimensión económica de su competitividad sustentable. La actividad turística, motor de la economía de Villa La Angostura y San Martín de los Andes, está experimentando síntomas de decrecimiento en muchos de sus indicadores. Esta crisis es paradójica porque presenta un escenario de aumento sostenido de la demanda, traducido en un aumento de la cantidad de visitantes y de la cantidad de pernoctes registrados, pero con un resultado global que sigue exhibiendo una disminución progresiva - y en el mejor de los casos estancamiento - de los porcentajes de ocupación de los establecimientos hoteleros y extra hoteleros, lo cual incide en la caída de la rentabilidad del negocio turístico. De hecho, en los últimos veinte años, ningún destino turístico del Corredor de los Lagos ha superado el $40 \%$ de ocupación promedio anual, incluso en contextos de incremento sostenido de la demanda turística. La típica estacionalidad que experimentan estos destinos complejiza aún más la situación.

La problemática de esta investigación es parte del abordaje que realiza el equipo de investigación de CEPLADES Turismo (IPEHCS-UNCo-CONICET), que desde el año 2005 ha estado investigando los procesos de movilidad por estilos de vida en la Argentina, especialmente en las áreas de montaña del norte de la Patagonia y también en algunas localidades turísticas del litoral Atlántico Argentino. En los últimos diez años la investigación se focalizó en el estudio de las distintas fases de desarrollo y cambio promovidos por estas movilidades en algunas localidades turísticas de Argentina consideradas paradigmáticas en relación a esos procesos, desarrollándose actualmente el proyecto "Migración de Amenidad en Destinos Turísticos de Montaña de la Norpatagonia. Transformaciones Territoriales e Innovaciones Culturales" (2014-2017).

\section{Consideraciones teóricas}

El anclaje teórico se basa, por un lado en las movilidades del post turismo, y por otro en la competitividad sustentable de destinos turísticos. El post turismo implica un cambio de estatus en las áreas y prácticas turísticas en el contexto de la globalización y la posmodernidad -es decir todo un fenómeno del "aquí-el allá" y la relación de intermediación 
entre ambos: la migración de amenidad (Moss, 2006), la migración por estilos de vida (Mclntyre, 2012) y las nuevas prácticas residenciales. El término fue acuñado por Maxine Feifer, quien en su obra "Going Places" de 1985 define al post turismo en términos del discernimiento de la actividad turística como un juego, cuyas reglas pueden ser manipuladas y reinventadas a voluntad, y cuyo disfrute proviene de la multiplicidad de experiencias que puede ofrecer, más que de la experimentación distintiva de una cultura "auténtica" (Huggan, 2001, p. 200). Aparecen algunas ideas que son centrales del post turismo: una primera noción de hipermovilidad a partir de la incidencia de las tecnologías de la comunicación, que sería luego trabajada en detalle por Castells (2000), y el sentido de los lugares para jugar y los lugares puestos en juego que sería central en The Tourist Gaze de John Urry (1990). El autor sugiere, en relación con el cambio observado en la modalidad de los viajes, que existe un paradigma cultural relativamente nuevo denominado "posturismo", como una manifestación del posmodernismo en el campo del turismo y dada sobre todo por el rechazo de las personas a ser tratadas como semejantes, con características y gustos similares, como sucede en el "turismo de masas".

El post turismo involucra nuevas formas de turismo contemporáneas que son resultado del cambio cultural y desarrollo tecnológico derivados del proceso de globalización. Hiernaux plantea que el espacio turístico es cada vez menos un espacio exclusivamente marcado por el turismo, del mismo modo que las actividades de ocio y turismo trastocan cada vez más los espacios supuestamente relacionados exclusivamente con el mundo de la producción. Eso es la llamada "turístificación" (Hiernaux, 2006, p. 425). Entre las formas esenciales del fenómeno del post turismo puede enumerarse la búsqueda de continuidades entre las prácticas recreativas, sociales, culturales, espaciales de las vacaciones y de la vida cotidiana, la mencionada "turistificación de los lugares comunes", el turismo experiencial, los tipos de prácticas híbridas que mezclan cuestiones profesionales, humanitarias y viajes, entre otras. La aceptación de un escenario de post-turismo, por lo tanto, señala lo trascendente de una visión que modifique cómo se entiende al turismo y sus prácticas cuando tanto la sociedad como las prácticas recreativas han evolucionado. Urry sugiere que en las sociedades "desarrolladas", a medida que se consolidan estos procesos, el turismo en su formato tradicional se disuelve como una práctica y un objeto autónomo (Urry, 2003, 2004). La buena vida, entendida como una vacación continua (Urry, 2003) y la jubilación como las vacaciones más largas de la vida (Rodríguez, 2001, p. 19), son ejemplos de las búsquedas de continuidades entre las prácticas vacacionales y la vida cotidiana, y por tanto, formas características y cotidianas de la hibridación turístico residencial típicas del post turismo. 
Los destinos turísticos deben ser analizados e interpretados como sistemas complejos donde se produce una intersección de múltiples movilidades, las propias del turismo y aquellas generadas por otras actividades económicas, profesionales o bien por los propios movimientos migratorios desde y hacia las localidades turísticas de montaña (Sheller, 2004; en Sheller y Urry, 2004, p. 6). Los destinos turísticos de montaña, en tanto lugares puestos en juego, pueden ser concebidos como lugares que son económica, política y culturalmente producidos, a través de la red de múltiples movilidades de capitales, personas, objetos, signos, y también de información (Sheller y Urry, 2004, p. 6). El carácter global de las movilidades del turismo implica un movimiento consumista de cuerpos, imágenes e información. Como resultado de estas movilidades, los lugares comienzan a ser consumidos a medida que son visitados o elegidos como nichos de mercado, unos tras otro en un proceso continuo de iguales características de consumo, hasta que finalmente resultan agotados, en el camino a la necesaria adquisición de características cosmopolitas, donde los lugares se alistan para reencarnarse en otros juegos, otros lugares y otras puestas en escena. En muchos casos, estas localidades turísticas se convierten en lugares llenos de sentimientos de decepción y frustración, cuando las expectativas de desarrollo personal, las puestas en juego previamente imaginadas, no pueden cumplirse (Sheller, en Sheller y Urry, 2004, p. 15).

McIntyre (2012) realiza una velada crítica a la investigación reciente sobre el fenómeno, argumentando que si bien reconoce la importancia de los vínculos entre movilidad y estilo de vida (Moss 2006; Benson y O'Reilly, 2009) ha restringido sus valoraciones a la migración o al desplazamiento de personas. Si bien la migración es un componente esencial de la movilidad, es sólo una entre variados tipos de movilidades (Urry, 2000) o flujos (Appadurai, 2008; Castells, 2000) que caracterizan a la modernidad reflexiva (Bones y Kesselring, 2004).

El trabajo ha considerado los antecedentes de investigaciones de CEPLADES sobre las movilidades del post turismo y sus incidencias en los destinos turísticos de montaña (González et al., 2008; González et al. 2009; Stefanick y González, 2012; Otero y González, 2014 y González y Otero, 2014).

Respecto de la competitividad, el trabajo parte del Modelo de Competitividad Sustentable de Destinos Turísticos propuesto por Ritchie y Crouch (2003), que propone una conceptualización de competitividad "con rostro humano", que además sintetiza los aportes de la teoría económica y social sobre el tema, al plantear un modelo dinámico para entender, analizar y trabajar los factores críticos de competitividad en destinos turísticos. El modelo conceptual reconoce la importancia de la sustentabilidad para el desempeño a mediano y largo plazo. En lo que se refiere a definiciones de competitividad, Ritchie y Crouch parten del reconocimiento acerca de la focalización inicial sobre las dimensiones económicas de la fortaleza y desempeño de un destino. Si bien el desempeño económico es relevante para la 
competitividad turística, es sólo una de las dimensiones a tener en cuenta. Por la naturaleza particular del sector turismo, la habilidad de un destino para competir también involucra sus fortalezas sociales, culturales, políticas, tecnológicas y ambientales. En definitiva, concluyen los autores "... lo que hace a un destino verdaderamente competitivo es su habilidad para incrementar el gasto turístico, aumentar la cantidad de visitantes, proveyendo experiencias memorables y satisfactorias, de una manera que resulte rentable, mejorando la calidad de vida de la población local, y preservando el capital natural del destino para las generaciones futuras..." (Ritchie y Crouch, 2003, p. 2). A partir de esta base, se han capitalizado los avances que sobre el tema de competitividad de destinos de montaña en el contexto del post turismo han realizado Sánchez y González (2011), González (2011), González et al. (2012) y González y Mantecón (2014).

\section{Consideraciones metodológicas}

El enfoque metodológico utilizado fue cuali-cuantitativo. Aunque en muchos momentos de la investigación predominó el enfoque cualitativo que permitió estudiar la complejidad del fenómeno y sus múltiples dimensiones desde las perspectivas de los actores involucrados, la estrategia cuantitativa apareció necesaria en otros momentos de la investigación, para el estudio de las evidencias de los condicionantes que la migración de amenidad impone sobre el desarrollo competitivo sustentable de estos destinos de montaña. El enfoque fue además necesariamente diacrónico y sincrónico.

Los destinos turísticos de montaña como unidades de análisis son lugares en los que la intervención turística promueve una multiplicidad de niveles de abordaje, por lo que el tratamiento de la información se realizó desde un enfoque de complejidad. Los aportes de la Geografía Crítica, en tanto plantea un espacio social relacional que es producto de la dinámica del capitalismo a escala global, regional y local, fueron claves para la investigación.

La selección de Villa La Angostura y San Martín de los Andes como casos de estudio se fundamenta en que son representativos de los procesos de migración de amenidad en el marco del post turismo. Aunque con matices, ambos destinos presentan patrones similares en su proceso fundacional, en su evolución y actualidad turística, y en el fenómeno de migración de amenidad que vienen experimentando desde la década del ochenta. El análisis del fenómeno en estas comunidades conforma un adecuado muestrario del post turismo en destinos de montaña del norte de la Patagonia, que entraña serios desafíos a la competitividad sustentable.

Respecto de las dimensiones de análisis, este trabajo consideró tres macro variables. Las dos primeras se refieren a un marco interpretativo del objeto de trabajo: la naturaleza y la 
dinámica del mercado del suelo en destinos turísticos de montaña, que incluyó entre otras dimensiones la demanda del suelo, los tipos de ofertas inmobiliarias y las modalidades de renta del suelo. Como complemento, la segunda macro variable fue la de los efectos regresivos derivados de la naturaleza de la renta del suelo sobre los destinos turísticos de montaña, que para el recorte temático de este trabajo incluyó como dimensiones críticas el crecimiento y expansión de la urbanización, la hibridación entre negocio turístico y negocio inmobiliario y la proliferación de barrios cerrados. Finalmente, la tercer macro variable, central de este trabajo, referencia a los factores críticos de competitividad sustentable de destinos turísticos de montaña, considerando la dimensión de rentabilidad de las empresas hoteleras. Para ellos se emplearon tres categorías analíticas en ambos casos: la ocupación promedio anual y su evolución, la evolución de la demanda turística (los indicadores empleados fueron la evolución en la cantidad de turistas arribados y la evolución en la cantidad de pernoctes turísticos) y la evolución de la oferta turística (cuyos indicadores fueron la evolución de la cantidad de establecimientos hoteleros habilitados, de la cantidad de plazas y de la cantidad de habitaciones turísticas).

El trabajo se basó en el análisis de datos secundarios (principalmente información demográfica e informes sectoriales nacionales, regionales y locales) y primarios (entrevistas focalizadas y en profundidad a los actores claves del proceso en ambos destinos de montaña). Esto permitió describir e interpretar comparativamente los datos existentes, construidos como resultado de la indagación documental, bibliográfica, testimonial, combinada con la observación participante y no patricipante en el ámbito en estudio. 


\section{Mapa 1}

Localización de Villa La Angostura y San Martín de los Andes en el Corredor de los Lagos y la Provincia de Neuquén

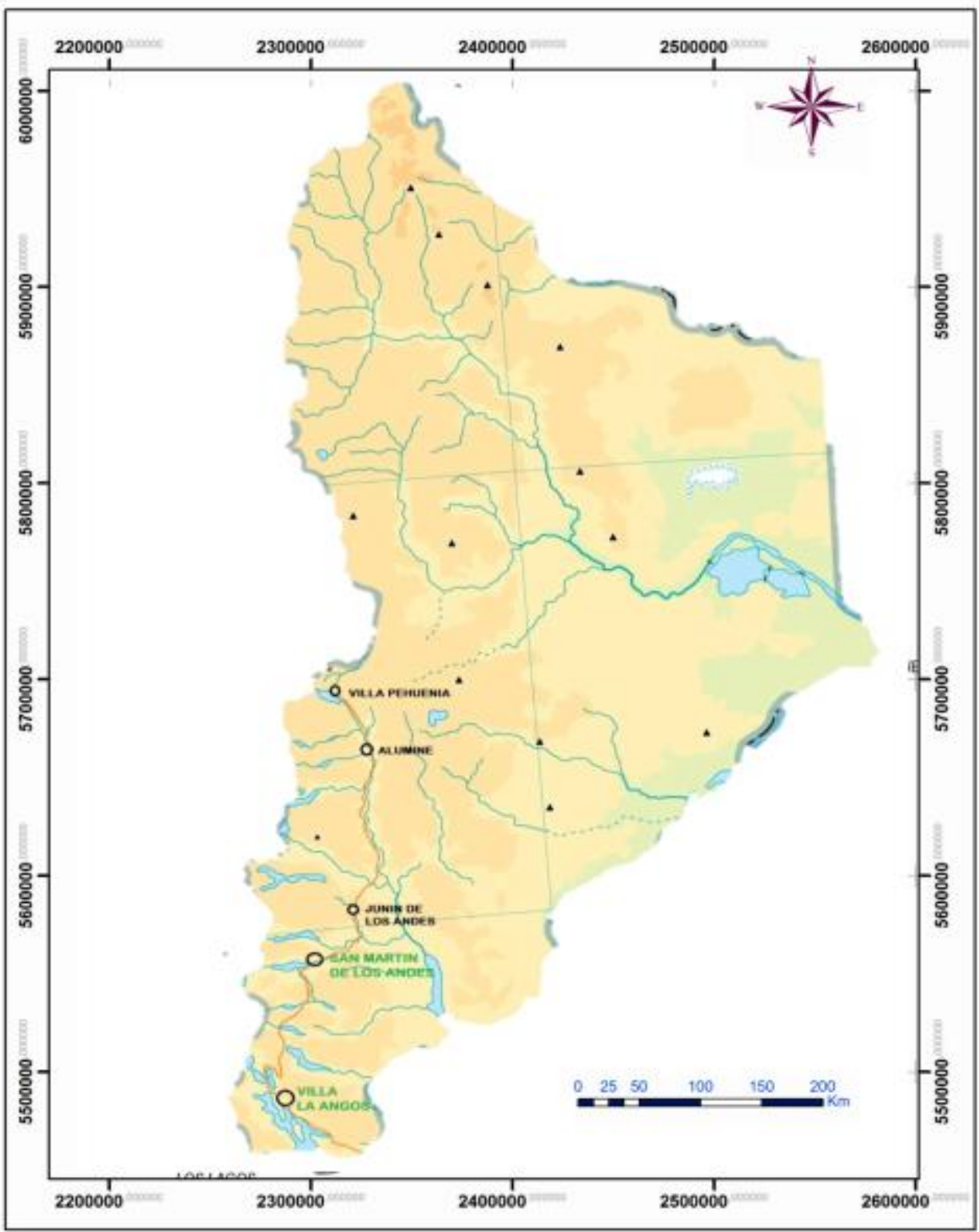

\section{El mercado inmobiliario guiado por la naturaleza de la renta del suelo}

La investigación abordó la naturaleza y accionar del mercado inmobiliario, por la relevancia que los incrementos de los valores del suelo y la vivienda han tenido en el contexto general de Argentina. La situación se presenta muy particularmente en los destinos turísticos de montaña del Corredor de los Lagos, en buena medida como correlato de las movilidades del post turismo. De hecho, ningún bien de consumo corriente ha experimentado un aumento 
de precios tan significativo como el suelo y la vivienda durante la primera década de este siglo (Baer, 2012).

El mercado del suelo urbano posee características distintivas, por las peculiaridades que posee el suelo como mercancía en las ciudades latinoamericanas: su relativa irreproductibilidad, dada por la dificultad de repetir su ubicación respecto a otras actividades de la sociedad; la preferencia de la demanda de suelo por unas pocas ubicaciones y la naturaleza inelástica de la oferta de suelo, lo que la configura como una oferta estructuralmente escasa (Morales Schechinger, 2007).

La naturaleza de la renta del suelo presenta dos particularidades que la definen: en primer lugar, no agrega valor al circuito económico. En segundo lugar, la renta se fija en función de un beneficio futuro y no de un valor de uso y cambio actual, siendo una inversión de muy bajo riesgo. La teoría de la renta, derivada de la economía clásica, plantea que ésta surge de un proceso competitivo por el suelo. La renta es captada por los dueños de la tierra y constituye un excedente sin relación con el esfuerzo productivo realizado por los propietarios (Arditi, Carrasco, Martínez y Sepúlveda, 2003). De acuerdo con lo anterior, el precio de mercado de los terrenos vacantes de una ciudad, se establece a partir de la tasa de ganancia que el propietario exige como su renta propia. Existe a su vez, la posibilidad de que la renta de un terreno se incremente a futuro. En esos casos, el propietario del suelo capitalizará en el precio esas rentas superiores; es decir que anticipará en el precio ese beneficio futuro. Se trata de una maximización constante de beneficios económicos, sin valor agregado y con relativo poco riesgo. Complementariamente, también es determinante en la formación del precio del suelo el producto inmobiliario que se decide construir para atraer a un cierto perfil de consumidor; es decir, lo que se construye encima de un lote (el tipo de uso que se habilita a partir de su acondicionamiento) constituye un componente de primer orden de la valorización inmobiliaria (Baer, 2012).

Este comportamiento del mercado del suelo promueve una serie de efectos regresivos sobre la estructura socioeconómica y espacial de las ciudades, tales como la dispersión urbana, la ciudad difusa y segregación y carencia de servicios. Asociado a ello, el crecimiento descontrolado de un mercado informal del suelo. En América Latina la informalidad de este sector es amplia, en parte dada la excesiva regulación del mercado que deja fuera a amplias capas de población. La lógica de la renta del suelo lleva además a una escasez física de terrenos, no sólo en términos absolutos sino también en términos relativos, si se piensa en la indisponibilidad de terrenos adecuadamente localizados. La escasez lleva finalmente a la retención, cuando al propietario le conviene atesorar el terreno en espera de un mayor y mejor uso futuro que le pague un precio mayor. La retención de tierras es un ejemplo de conducta 
patrimonialista en la que participan todo tipo de propietarios cuando el entorno del mercado es desregulado y desgravado (Morales Schechinger, 2007).

Estas particularidades de la renta del suelo, que conocen y manejan tan bien los agentes inmobiliarios, son los factores que guían el accionar del negocio inmobiliario hacia un círculo vicioso de incremento del valor de venta, sin agregar valor al circuito económico y, por ende, disparando el accionar inmobiliario en los procesos de urbanización en sus tres fases: expansión, crecimiento y densificación. Entender la naturaleza de la renta de la tierra es fundamental para poder trabajar en la dirección de los destinos con crecimiento y expansión urbana a partir de los procesos de movilidades derivados del post turismo.

\section{El avance del negocio inmobiliario en el Corredor de los Lagos}

La lógica del mercado del suelo reconoce sus propias manifestaciones y repercusiones en los destinos turísticos de montaña del Corredor de los Lagos. Esta lógica ha desencadenado la aceleración de su proceso de expansión urbana. En Villa La Angostura y San Martín de los Andes los loteos - destinados en su mayoría a barrios cerrados o countries dan cuenta de un crecimiento urbano con bajo nivel de políticas públicas y de regulación del suelo, lo que promueve el avance de la trama urbana. Esta búsqueda por maximizar las ganancias de los productos urbanos lleva a los desarrolladores a elegir tierras en la periferia, donde la provisión de infraestructura y de servicios se convierte en un desafío para el Estado.

Las tres fases de crecimiento urbano que destaca Garay (1996): expansión, consolidación y densificación, se presentan tanto en Villa La Angostura como en San Martín de los Andes en una distinguible secuencia cronológica que comienza a mediados de los años noventa y avanza rápidamente hacia las últimas dos fases. En ambos casos, la dispersión de los procesos urbanos promueve el avance de la frontera urbana sobre áreas frágiles: las laderas de montañas y cerros, las áreas de bosque, de mallines y de ribera (ver Figura 1).

Una forma recurrente de expansión y consolidación es el barrio cerrado. En tanto producto urbano, expresa una forma de vida de autosegregación y plantea una serie de cuestiones adversas en términos de integración social, física y urbana. Su proliferación en los espacios de montaña genera una imagen urbana dispersa, perdiendo calidad en los recursos escénicos del paisaje, sobre todo en áreas de laderas y en las áreas cercanas a cursos de agua (Otero y Gallego, 2006). El avance de la construcción de countries en estos destinos de montaña, fundamentalmente dirigidos a los migrantes de amenidad o por estilos de vida, implica la comodificación del medio ambiente en la medida en que es apropiado por parte de los desarrolladores inmobiliarios para destinarlo a usos urbanos, privatizando las prácticas turísticas en ellos propuestas. 


\section{Figura 1}

\section{Expansión urbana en Villa La Angostura 1989-2009}

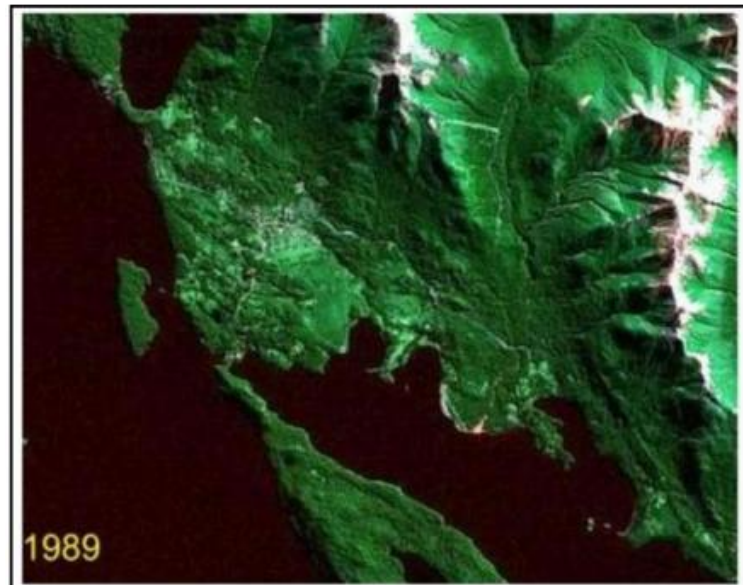

Expansión Urbana de Villa la Angostura de los últimos 20 años

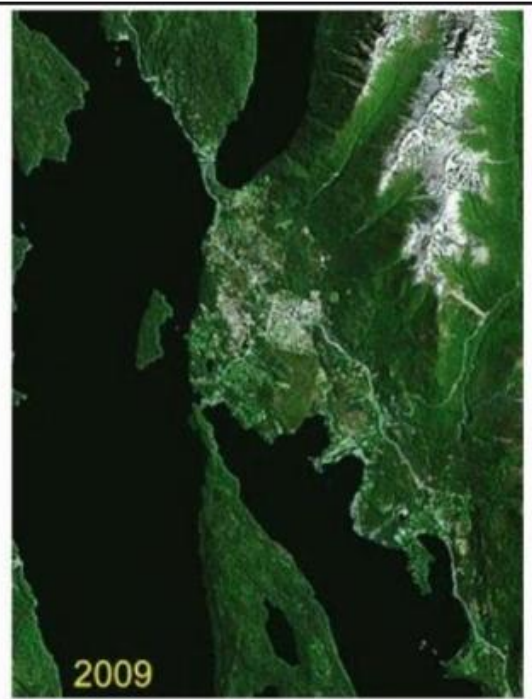

(R:1 G.5 871969 Natestal Procesade 2009 EOSAT Fast RS 1) Fuente CONAE

Fuente: Merlos (2012)

Villa La Angostura, destino de migraciones y negocio inmobiliario

Para indagar en las huellas de la operatoria y lógica del negocio inmobiliario en Villa La Angostura, la investigación planteó una caracterización del producto inmobiliario, considerando, entre otras, las siguientes dimensiones: cantidad de productos inmobiliarios ofrecidos, tipos de desarrollos, localización del producto inmobiliario, producto inmobiliario y urbanizaciones privadas. El primer dato notorio fue - al mes de Abril de 2014 - un total de 831 productos inmobiliarios ofertados en el mercado inmobiliario formal, en una localidad cuya población, de acuerdo a cifras del último Censo 2010, era de 11.063 habitantes; esto representa una relación producto inmobiliario/habitante de 1 (un) producto inmobiliario cada 13 personas. Esta relación es elocuente del peso del negocio inmobiliario en la economía local.

El interés en la renta inmobiliaria por propio peso acaba desplazando a las otras actividades económicas productivas. La financiarización de la economía, instrumentada a través de un maridaje entre los sectores financiero e inmobiliario, es el motor de este fenómeno especulativo.

Los lotes y las fracciones conforman casi la mitad de esa oferta total, dado que son los más buscados y los que se ajustan a ese segmento de personas que se mudan buscando encontrar la nueva vida, empezando por la compra de un terreno. A la oferta de lotes y fracciones le siguen en importancia la oferta de venta de casas y cabañas con el $36 \%$. Esto se explica por las búsquedas de productos urbanos de parte de los migrantes de amenidad 
relacionados a la vivienda, la mudanza, el nuevo hogar. Muchos de estos loteos se localizan en barrios cerrados y privados, lo que implica un avance privatizador y de presión sobre los llamados "bienes comunes", que es ya característica de Villa La Angostura. La presión continua del mercado inmobiliario para avanzar sobre espacios públicos, está dada por un Estado que deja actuar y aprueba esos proyectos, pero también por la gradual consolidación de lo que podría llamarse un paradigma inmobiliario, que se empieza a instalar como socialmente aceptado por parte de la población local y sus representantes.

El predominio de esta industria de ladrillos y la expansión urbana tienen algunas causas concretas, que deben buscarse en la mecánica de las excepciones y las modificaciones a las normativas vigentes. El Código de Urbanización y otras normas anexas sufren usualmente modificaciones a partir de requerimientos del negocio inmobiliario. En 2013, por caso, se modificaron ciertos puntos de la normativa que permiten ampliar las medidas de construcción por metro cuadrado, lo que habilita a las inmobiliarias a realizar construcciones más grandes dentro de los lotes. Entran en juego aquí no sólo el poder de negociación y lobby del sector, sino también la consideración de que "todo crecimiento es positivo", discurso que permea en sectores de la comunidad local y en sus representantes políticos.

El aumento poblacional de la villa a partir de la llegada de migrantes de amenidad desde mediados de los noventa, indujo a un aumento de la demanda de productos inmobiliarios y, consecuentemente, al aumento de la oferta orientada a dar respuesta a esa demanda. Esto toca una de las dimensiones de la competitividad sustentable de destinos turísticos (Crouch y Ritchie, 2003): Las condiciones de gestión del destino. El reconocimiento por parte de las autoridades locales acerca de que Villa La Angostura está pasando de ser un destino turístico a un destino habitacional, de alguna manera legitima la hibridación entre la función residencial y turística característica de las movilidades del post turismo en esta comunidad. Pero más allá del reconocimiento de la problemática, no son pocos los actores locales que tienen una visión del Estado como promotor más que regulador y controlador de esta industria del ladrillo.

El protagonismo del negocio inmobiliario por sobre la actividad turística en la villa trajo aparejado una secuencia de problemas: la lógica en apariencia contrapuesta de dos modelos de desarrollo, el crecimiento continuo de los proyectos inmobiliarios, la modificación de normas y ordenanzas, el individualismo de algunos sectores de la población local; en cuanto a lo turístico, la primacía del sector alojamiento por sobre otros servicios que deberían diversificar la oferta y no lo hacen, y sobre todo, una crisis de rentabilidad aún no plenamente asumida o reconocida. 
La expansión del negocio inmobiliario como nuevo motor de la economía local debería llevar al sector turismo a considerar la necesaria diversificación de la estructura servuctiva, es decir, a poder encontrar formas de salir de la trampa de un destino caro y aburrido. No se ha innovado en materia de nuevos productos ni experiencias significativas; el sector público se ha inclinado a proyectos de desarrollo de infraestructura que generen mano de obra y fuentes de empleo, ha invertido poco y nada en liderar procesos de innovación y agregación de valor que diferencien y refuercen la atractividad del destino.

\section{La expansión de la mancha urbana en San Martín de los Andes}

En San Martín de los Andes, el fuerte crecimiento demográfico y turístico de las década de los ochenta y noventa distorsionó el patrón de crecimiento hasta entonces equilibrado, conformado por las actividades urbanas en las cercanías del lago Lácar y la explotación primaria en el resto del ejido. Este aumento de población produjo la habilitación de tierras de uso rural o en estado rústico para ser urbanizadas (Gallego, Molins y Dupen, 2014). El patrón de uso de la tierra revela la pérdida de espacios rurales y un aumento de la subdivisión de espacios para destinarlos a la construcción. La expansión urbana va de la mano del desarrollo de productos urbanos de tipo turístico-residenciales en la forma de barrios cerrados. San Martín de los Andes está teniendo un crecimiento urbano-territorial en sentido norte-noreste: hacia el norte, sobre el eje de la Ruta Provincial 62 que comunica con el lago Lolog, y hacia el noreste, sobre el eje de la Ruta Nacional 40, en dirección a Junín de los Andes, haciendo pensar que en un futuro no muy lejano ambas manchas urbanas lleguen a conformar una sola conurbación (ver mapa 2). Esta lógica de construir ciudad a partir de los proyectos de productos urbanos privados va configurando una trama dispersa, haciéndose visible cada vez más la fragmentación urbana, con "parches" de urbanizaciones dentro y fuera del ejido urbano de San Martín de Los Andes.

Un elemento distintivo de estos countries es su localización en los límites del ejido municipal, de manera de maximizar ganancias respecto al valor del suelo. Estudiando los productos urbanos de San Martín de los Andes, Hurstel (2013) indica que la distancia mínima al casco urbano ronda entre los 6-7 km, mientras que la distancia máxima es de $14 \mathrm{~km}$ aproximadamente. A su vez, estas distancias denotan la falta de conectividad a la red urbana de tratamiento de efluentes cloacales, aspecto que da cuenta de una visión poco sustentable del modelo urbano en el que se inscribe la localidad, que se construye desde una lógica privada. La búsqueda de estas microlocalizaciones coincide con lo señalado por Garay (1996), quien menciona que "el mercado de suelo es un mercado de localizaciones: el precio está condicionado por lo que sucede en el entorno inmediato, en el barrio y por su inserción en el 
contexto urbano más amplio". Es así como el mercado inmobiliario es quien orienta el crecimiento turístico (principalmente con las amenities que se ofrecen dentro de los desarrollos urbanos) y por ende de este destino de montaña. Esto da como resultado un crecimiento urbano cada vez más fragmentado, donde existen grandes "distancias" en cuanto a la infraestructura urbana, generando una suerte de islas que rompen la continuidad y generan muchos conflictos sociales entre los habitantes de una misma ciudad.

\section{Mapa 2}

\section{Ejido urbano de San Martín de los Andes} Neuquén, Argentina. 2015

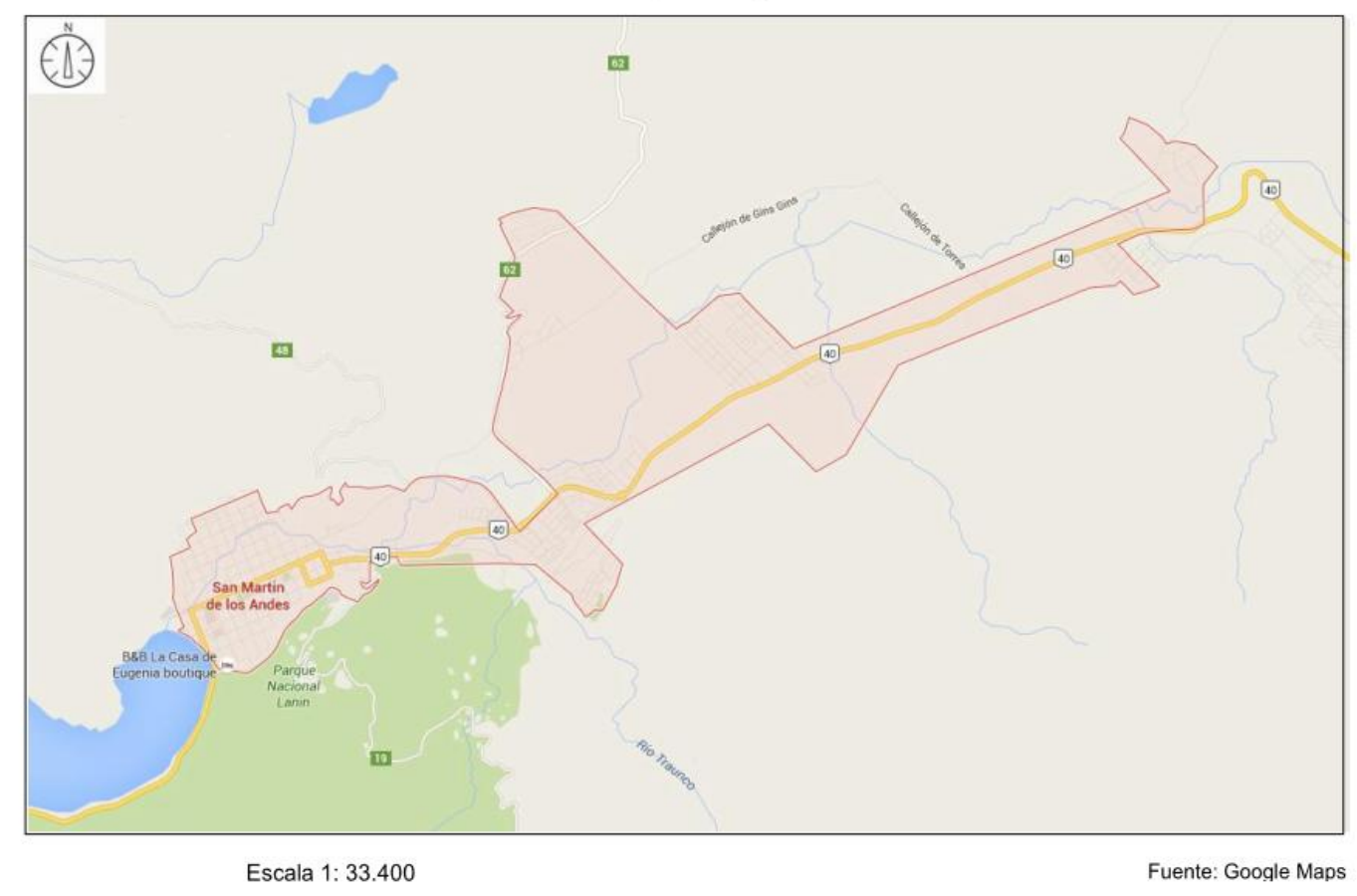

\section{La paradójica crisis de rentabilidad en el Corredor de los Lagos}

La competitividad sustentable tiene en la rentabilidad su base económica indispensable para lograr que el turismo pueda ser considerado una alternativa viable para las comunidades de montaña. A continuación se presentan evidencias de una crisis de rentabilidad en Villa La Angostura y San Martín de los Andes.

La burbuja de crecimiento y los desafíos de la rentabilidad turística en Villa La Angostura

En Villa La Angostura se presenta la paradoja de una disminución y, en el mejor de los casos, un estancamiento en el indicador clave de rentabilidad turística como es el porcentaje 
de ocupación promedio anual, aún en una situación de progresivo y sostenido aumento de la demanda turística.

En términos nominales, la demanda turística no cesó de crecer, atraída por el posicionamiento de la villa como destino turístico, sobre todo a partir de la segunda mitad de la década de los noventa, fundamentalmente luego de la crisis económica del 2001 y la recuperación de la actividad desde 2003.

En el período 2002-2006, por caso, prácticamente se duplicó la cantidad de pernoctes registrados en la villa (de 260.315 en 2002 a 400.335 en 2006) y de turistas alojados (de 67.753 en 2002 a 80.067 en 2006). Sin embargo, la ocupación promedio anual de su planta de alojamiento nunca superó el 40\%. En los últimos años estas tendencias se consolidaron. Entre 2007 y 2011, en Villa La Angostura se produjo un descenso del porcentaje de ocupación de la temporada alta estival, de un $88,24 \%$ a un $81,52 \%$. Entre 2007 y 2014 , la ocupación promedio anual nunca superó el orden del $40 \%$ y sólo una vez estuvo por encima de los 35 puntos porcentuales, en 2013 (ver Tabla $N^{\circ} 1$ ). En el mismo período, continuó la tendencia de aumento de nuevos establecimientos hoteleros y plazas turística (ver Tabla $\mathrm{N}^{\circ} 2$ ).

Tabla $\mathrm{N}^{\circ} 1$

Factor de ocupación de plazas y habitaciones turísticas en Villa La Angostura 2007-2014.

\begin{tabular}{|c|c|c|c|c|c|c|c|c|}
\hline \multirow[t]{2}{*}{ Factor ocupación anual } & \multicolumn{8}{|c|}{ Año } \\
\hline & 2007 & 2008 & 2009 & 2010 & 2011 & 2012 & 2013 & 2014 \\
\hline Plazas turísticas & $34,18 \%$ & $32,04 \%$ & $30,56 \%$ & $34,64 \%$ & $29,40 \%$ & $29,19 \%$ & $38,12 \%$ & $53,29 \%$ \\
\hline Habitaciones turísticas & $41,17 \%$ & $40,18 \%$ & $35,58 \%$ & $41,91 \%$ & III & $33,91 \%$ & $44,98 \%$ & $57,29 \%$ \\
\hline
\end{tabular}

Fuente: Elaboración propia en base a datos estadísticos de la Subsecretaría de Turismo de la Provincia de Neuquén

Tabla $\mathrm{N}^{\circ} 2$

Variación interanual de cantidad de establecimientos y plazas turísticas

Villa La Angostura 2007-2013

\begin{tabular}{|c|c|c|c|c|c|c|c|}
\hline \multirow[b]{2}{*}{ Indicador } & \multicolumn{7}{|c|}{ Período } \\
\hline & $\begin{array}{l}2007- \\
2006\end{array}$ & $\begin{array}{c}2008- \\
2007\end{array}$ & $\begin{array}{c}2009- \\
2008\end{array}$ & $\begin{array}{c}2010- \\
2009\end{array}$ & $\begin{array}{c}\text { 2011- } \\
2010\end{array}$ & $\begin{array}{c}2012- \\
2011\end{array}$ & $\begin{array}{c}2013- \\
2012\end{array}$ \\
\hline \multicolumn{8}{|l|}{ Establecimientos } \\
\hline Variación absoluta & 11 & 2 & 7 & 5 & 4 & - & 2 \\
\hline Variación Porcentual & $8,40 \%$ & $1,41 \%$ & $4,86 \%$ & $3,31 \%$ & $-2,56 \%$ & - & $1,32 \%$ \\
\hline \multicolumn{8}{|l|}{ Plazas } \\
\hline Variación absoluta & 257 & 100 & 209 & 83 & 111 & 2 & 101 \\
\hline Variación Porcentual & $7,36 \%$ & $3,67 \%$ & $5,43 \%$ & 2,05 & $-2,68$ & 0,05 & 2,50 \\
\hline
\end{tabular}

Fuente: Elaboración propia en base a datos estadísticos de la Subsecretaría de Turismo de la Provincia de Neuquén

Las evidencias son contundentes: decrece la ocupación promedio anual de plazas y habitaciones al ritmo de un aumento sostenido de la oferta, pero siempre en un contexto 
paradojal de aumento sostenido de la cantidad de visitantes llegados al destino. Las causas pueden encontrarse en un claro sobredimensionamiento de la oferta por sobre la demanda turística. En Villa La Angostura este no es un fenómeno nuevo; el sobre aumento de la oferta, aunque se ha intensificado en los últimos doce a quince años, data cuanto menos de 25 años atrás. El incremento porcentual acumulado de plazas habilitadas en Villa La Angostura fue del $2364 \%$ desde 1964, primer año de registro. Pero tal vez el dato más significativo sea que la oferta de plazas aumentó un 588\% en los últimos 20 años, a partir del inicio y consolidación de este fenómeno a principios de la década de los noventa. Asimismo, registró un aumento del $90,35 \%$ desde la crisis de 2001 . Esto implica que, a datos de 2015 , el $78 \%$ de los establecimientos hoteleros son relativamente nuevos, con una antigüedad de 10 años o menos.

Landriscini (2008) refiere a este fenómeno como una "burbuja de crecimiento exógeno", que atrajo inversiones a la villa orientadas a la construcción de emprendimientos hoteleros, las cuales hoy no son rentables, y evidencian una baja generación de empleo y de carácter estacional. El crecimiento poblacional se triplicó en Villa La Angostura entre 2001 y 2010 . El aumento de pobladores tuvo como correlato un aumento sostenido de nuevos establecimientos hoteleros y por ende de las plazas hoteleras. Buena parte de ese aumento exagerado de la oferta turística se explica por un fenómeno que lo abarca, como es la llegada a la villa de nuevos migrantes transformados en nuevos inversores turísticos, lo que permite avalar la hipótesis de Landriscini.

Este crecimiento de la oferta ha resultado tan crítico, que terminó superando incluso el incremento de la demanda. La oferta turística hotelera creció, de 1857 plazas en 1999 a 4161 en 2013, significando un incremento acumulado del 224\%, que en buena medida explica el amesetamiento y hasta el decrecimiento de la rentabilidad hotelera traducida en porcentajes de ocupación en un contexto de crecimiento sostenido de demanda.

La investigación proveyó un dato que refleja la incidencia de la hibridación entre la función residencial y la función turística en Villa La Angostura: entre 2001 y 2008 los metros cuadrados residenciales construidos superaron a aquellos dedicados a construcciones vinculadas al turismo. Esto da cuenta de un proceso de transición en los últimos años, de un perfil de villa turística de montaña a un destino de migración de amenidad.

En el año 2011 el proceso quedó aún más evidenciado. La erupción del complejo volcánico Caulle-Puyehue en Mayo de ese año, precipitó todos los indicadores; prácticamente desapareció la temporada invernal ( $7 \%$ de ocupación en Julio, y poco más de $10 \%$ de ocupación en Agosto, con una leve mejoría en Septiembre con un 17\%). Con esto, los índices de rentabilidad de ese año fueron muy bajos: la ocupación promedio anual de 2011 fue de un $29,40 \%$. Ya en 2012, se produjo una leve mejoría en estos indicadores de la mano de una 
campaña de reposicionamiento del destino, aunque la ocupación promedio anual de plazas sólo alcanzó un 33,29\%. A partir de entonces, el crecimiento de la oferta turística continuó sostenidamente y sólo registró números negativos luego de la explosión del volcán. Este análisis permite apreciar que la decisión de nuevas inversiones que incrementan la oferta de alojamiento no sólo no es sensible a las fluctuaciones de los porcentajes de ocupación, sino que se muestra inelástica ante acontecimientos inesperados graves.

A esta crisis de rentabilidad se suman otros condicionantes a la competitividad económica de estos destinos de montaña. Se presentan aspectos críticos en indicadores económicos claves, como la generación de empleo. En Villa La Angostura el tamaño de los emprendimientos es un condicionante, ya que se trata en su mayoría de empresas familiares que en promedio no superan las 28 plazas, lo que incide en una baja generación de empleos directos. De acuerdo a datos del Plan de Ordenamiento Territorial y Ambiental de Villa La Angostura de 2007, pero que no han variado sustancialmente a la fecha, la generación de empleo de la actividad turística es muy baja: entre el $42,3 \%$ y el $61 \%$ de los establecimientos tenían uno o ningún empleado; entre el 30,9\% y el $42,3 \%$ entre 2 y 5 empleados y sólo entre el $8,1 \%$ y el $15,4 \%$ tenían más de 5 empleados. A la naturaleza familiar y el tamaño de las empresas turísticas, se suman tres factores que hacen aún más complejo el panorama: el carácter estacional de los mismos por las bajas remuneraciones y los altos requisitos de capacitación del sector. Esto tiene mayor impacto en los sectores asalariados de estas comunidades por el alto costo de vida en estas ciudades. El carácter estacional de la demanda laboral contribuye aún más a la precarización del empleo.

En definitiva, la baja generación de empleo, mayormente informal, temporario y con bajas remuneraciones, redunda en una compleja situación de precarización laboral y de reducción de los ingresos de los trabajadores, muchos de los cuales se sintieron atraídos por la promesa de un futuro laboral floreciente en el sector turismo que hoy en día ya no es tal. El resultado es el progresivo empobrecimiento de un importante sector de la comunidad conformado por trabajadores cuentapropistas, trabajadores estacionales, pequeños comerciantes y prestadores de servicios, así como antiguos residentes.

\section{Las evidencias de la crisis de rentabilidad en San Martín de los Andes}

En San Martín de los Andes se encontraron indicadores similares a los analizados en Villa La Angostura. Si se consideran los últimos 25 años, la cantidad de pernoctes prácticamente se triplicó. Sin embargo, la ocupación promedio anual del destino casi siempre se mantuvo por debajo del $40 \%$ anual en ese período, con una máxima del $40,8 \%$ en 2007 y un registro mínimo del 24,4\% en 1992 (ver Tabla №3). La explicación de este aparente 
contrasentido radica en que, para el mismo período, la cantidad de plazas habilitadas aumentó en un $229 \%$. Nuevamente, el sobre aumento de la oferta por sobre la evolución positiva de la demanda impidió horizontes de rentabilidad para las empresas turísticas. Tampoco en este caso el crecimiento de la oferta es un tema nuevo: desde que comenzaron los registros en 1973 hasta 1990, la oferta de establecimientos aumentó sólo un 32\% en poco menos de 20 años. Es en los años noventa cuando se produjo el mayor aumento: entre 1990 y 2001, la oferta hotelera creció un $87 \%$, y en la década siguiente, siguió creciendo a un ritmo más lento del orden del $58 \%$. En total, desde inicios de la década del noventa, se triplicó la cantidad de establecimientos habilitados en el destino. El patrón es similar al presentado para Villa La Angostura: descenso de los porcentajes de ocupación, en un contexto de aumento de la cantidad de turistas arribados al destino, pero con un aumento aún mayor de la oferta hotelera por sobre esa demanda.

En el mismo período, las plazas turísticas también crecieron, pero en menor porcentaje: $145 \%$.También se registra ese notorio aumento en la década de los noventa (un crecimiento del $92,72 \%$ de plazas entre 1990 y 2001), pero descendiendo mucho ese crecimiento en la década siguiente, sólo el $27 \%$. Este contraste permite una consideración adicional: en los últimos años, creció más la oferta de establecimientos que de plazas, y esto lleva a pensar en la cuestión del tamaño de los proyectos hoteleros introducidos al mercado; como en el caso de Villa La Angostura, se trata de pequeñas empresas con menos habitaciones y plazas, manejados como empresas familiares, con pocos empleados y lento recupero de la inversión, que incide aún más en la percepción de una crisis de rentabilidad del sector hotelero en estos destinos turísticos de montaña.

Luego, actualizando los datos a 2013, se aprecia una remontada del porcentaje de ocupación, a partir del aumento de la demanda, pero también, y por primera vez desde que se tienen registros estadísticos, de una disminución interanual en la cantidad de nuevos establecimientos y plazas ofrecidas.

Una mirada al desempeño del destino en términos de su atractividad escondería el problema, ya que la demanda turística no ha cesado de crecer. El análisis de los datos de los mejores años en términos de afluencia de turistas en los últimos 25 años, 2007 a 2010, permite apreciar hasta qué punto el decrecimiento de los factores de ocupación se explica en buena medida por el sobre aumento de la oferta. En efecto, de 2007 a 2010 se produjo un aumento del $8,20 \%$ en la llegada de visitantes a SMA; sin embargo, para el mismo período, fue aún mayor el crecimiento de la oferta hotelera, alcanzando un $12,68 \%$, esto es, un $4,48 \%$ por encima del crecimiento de la demanda (ver Tabla $N^{\circ} 4$ ). En este período, la cantidad de pernoctes descendió un $0,5 \%$, pero mucho más lo hizo el porcentaje de ocupación promedio donde incide el aumento de establecimientos y plazas- que se redujo en términos del $3,45 \%$. 
Tabla $\mathrm{N}^{\circ} 3$

Evolución de cantidad de pernoctes, plazas habilitadas y ocupación promedio anual de plazas turísticas, San Martín de los Andes 1990-2009

\begin{tabular}{|c|c|c|c|}
\hline Años & $\begin{array}{c}\text { Cant.de } \\
\text { pernoctes }\end{array}$ & Plazas habilitadas & $\begin{array}{c}\text { Ocupación } \\
\text { promedio anual } \\
(\%)\end{array}$ \\
\hline 1990 & 199309 & 2941 & 26,1 \\
\hline 1991 & 219156 & 3014 & 25,7 \\
\hline 1992 & 233261 & 3428 & 24,4 \\
\hline 1993 & 293601 & 3738 & 27,4 \\
\hline 1994 & 376351 & 3780 & 31,6 \\
\hline 1995 & 382152 & 3918 & 30,7 \\
\hline 1996 & 380550 & 4104 & 29 \\
\hline 1997 & 422019 & 4532 & 30 \\
\hline 1998 & 535899 & 4644 & 33,8 \\
\hline 1999 & 521612 & 5237 & 30,1 \\
\hline 2000 & 492256 & 5553 & 27,2 \\
\hline 2001 & 484858 & 5668 & 25,3 \\
\hline 2002 & 623238 & 5825 & 32,5 \\
\hline 2003 & 695201 & 5533 & 36,5 \\
\hline 2004 & 755160 & 5697 & 39,5 \\
\hline 2005 & 720140 & 5838 & 37,5 \\
\hline 2006 & 781068 & 6026 & 39 \\
\hline 2007 & 856533 & 6236 & 40,8 \\
\hline 2008 & 786742 & 6744 & 35,7 \\
\hline 2009 & 599704 & 6757 & 34,3 \\
\hline 2010 & 891491 & 7214 & 36,60 \\
\hline 2011 & 803877 & 7166 & 30,28 \\
\hline 2012 & 790316 & 6851 & 30,56 \\
\hline 2013 & 996281 & 6754 & 39,58 \\
\hline
\end{tabular}

Fuente: Elaboración propia en base a datos de la Subsecretaria de Turismo de la Provincia de Neuquén y de la Secretaría de Turismo y de Desarrollo Económico de la Municipalidad de San Martín de los Andes

Tabla $\mathrm{N}^{\circ} 4$

Variación conjunta de la demanda turística y de la cantidad de plazas habilitadas y su repercusión en la ocupación promedio anual de San Martín de los Andes, 2007-2010.

\begin{tabular}{|c|c|c|}
\hline 2007 & 2010 & Variación \% \\
\hline \multicolumn{3}{|c|}{ Cantidad de Turistas arribados } \\
\hline 176.211 & 190.676 & $8,20 \%$ \\
\hline \multicolumn{3}{|c|}{ Cantidad de plazas habilitadas } \\
\hline 6289 & 7087 & $12,68 \%$ \\
\hline
\end{tabular}




\begin{tabular}{ccc}
895.894 & 891.491 & $-0,5 \%$ \\
\hline Porcentaje de ocupación promedio anual \\
\hline $40,05 \%$ & $36,60 \%$ & $-3,45 \%$ \\
\hline Fuente: Elaboración propia en base a datos oficiales de Neuquén Tur
\end{tabular}

Para completar las evidencias de este sobre aumento de oferta, basta decir que para el mismo período 2007-2010, la variación porcentual acumulada en la cantidad de establecimientos habilitados fue de un $21,07 \%$, mientras que el crecimiento porcentual acumulado de nuevas plazas habilitadas fue del orden del $18,24 \%$, lo que estuvo claramente por encima de la cantidad de turistas arribados y sobre todo de la variación negativa de pernoctes registrados en el mismo período. Si se extiende al período 2005-2013, los resultados fueron un poco más drásticos: la variación porcentual acumulada de establecimientos trepó al 37,13\%, mientras que la variación porcentual acumulada de plazas se mantuvo en la cifra anterior $(18,85 \%)$ aún cuando se registró un descenso acumulado de cantidad de plazas del orden del 6,49\% en los últimos tres años (Ver Tabla $N^{\circ} 5$ ).

Tabla $\mathrm{N}^{\circ} 5$

Variación interanual de cantidad de establecimientos y plazas turísticas

San Martín de los Andes 2006-2013

\begin{tabular}{|c|c|c|c|c|c|c|c|c|}
\hline \multirow[b]{2}{*}{ Indicador } & \multicolumn{8}{|c|}{ Período } \\
\hline & $\begin{array}{l}2006- \\
2005\end{array}$ & $\begin{array}{l}2007- \\
2006\end{array}$ & $\begin{array}{l}2008- \\
2007\end{array}$ & $\begin{array}{l}2009- \\
2008\end{array}$ & $\begin{array}{c}2010- \\
2009\end{array}$ & $\begin{array}{l}2011- \\
2010\end{array}$ & $\begin{array}{l}2012- \\
2011\end{array}$ & $\begin{array}{l}2013- \\
2012\end{array}$ \\
\hline \multicolumn{9}{|l|}{ Establecimientos } \\
\hline Variación absoluta & 18 & 10 & 19 & 8 & 2 & -5 & -11 & -3 \\
\hline Variación Porcentual & $11,61 \%$ & $5,78 \%$ & $10,38 \%$ & $3,96 \%$ & $0,95 \%$ & $-2,36 \%$ & $5,31 \%$ & $1,53 \%$ \\
\hline \multicolumn{9}{|l|}{ Plazas } \\
\hline Variación absoluta & 402 & 243 & 611 & 168 & 146 & -48 & -315 & -97 \\
\hline Variación Porcentual & $7,12 \%$ & $4,02 \%$ & $9,72 \%$ & $2,43 \%$ & $2,07 \%$ & $-0,67 \%$ & $-4,40 \%$ & $-1,42 \%$ \\
\hline
\end{tabular}

Fuente: Subsecretaría de Turismo de la Provincia de Neuquén y Secretaría de Turismo y de Desarrollo Económico de la Municipalidad de San Martín de los Andes

El descenso de la oferta a partir del 2010, ha ayudado a recuperar un poco los porcentajes de ocupación, lo que es una evidencia del impacto que el exceso de oferta tiene sobre porcentajes de ocupación y rentabilidad hotelera. Sin embargo, es dable considerar que se han considerado las cifras de ocupación de alojamientos habilitados; los problemas de rentabilidad se vuelven más críticos cuando se considera a la oferta real, es decir, a ese casi $40 \%$ de alojamientos no registrados que engrosan la oferta hotelera del destino.

La generalización de la problemática: caída de rentabilidad por sobre aumento de la oferta turística en el Corredor de los Lagos y la Provincia de Neuquén 
La crisis de rentabilidad por sobre aumento de la oferta turística es una realidad generalizable a la mayoría de los destinos turísticos de montaña del Corredor de los Lagos, aún en aquellos que se encuentran en otras fases de sus ciclos de vida. El aumento en la cantidad de plazas turísticas habilitadas es sostenido para el período 2006-2013, con algunos casos extremos: en Aluminé y Villa Pehuenia más que se duplica la oferta de plazas en menos de cinco años, y en Junín de los Andes y Caviahue se presentan cifras que abonan el mismo fenómeno, siempre derivadas de un sobre aumento de oferta. Resulta notorio que aquellos destinos que más han aumentado su oferta, como Aluminé (casi el 140\% de aumento de plazas en menos de 7 años) y Junín de los Andes (82,05\% de aumento de plazas), son los que más bajos porcentajes de ocupación detentan (25,28\% y $24,76 \%$ respectivamente). Villa La Angostura y San Martín de los Andes son los que mejor desempeño muestran comparativamente. Esto sucede, tal vez, porque simplemente han llegado a un techo de crecimiento, o como en el caso de San Martín de los Andes, cambios en la normativa y exagerado aumento de las habilitaciones turísticas ha llevado a que recién a partir de 2011 comenzara a revertirse la tendencia de aumento de oferta: SMA disminuyó su crecimiento de plazas en más de 5 puntos comparando los períodos 2006-2010 (16,9\% de incremento de plazas) y 2006-2013, donde el incremento fue del orden del $11,17 \%$, el más bajo del todo el Corredor de los Lagos. Una nota especial cabe para el caso de Junín de los Andes. Su exagerado sobre aumento de oferta sin dudas es el resultado de la captación de inversiones en desarrollo de oferta, derivada del proceso de expansión urbana de San Martín de los Andes, que ha llevado a la notoria expansión de la mancha urbana. San Martín de los Andes crece hacia Junín de los Andes y arrastra en ese crecimiento esta problemática hacia su vecino.

Tabla $\mathrm{N}^{\circ} 6$

Crecimiento de la oferta de plazas habilitadas 2006-2013, y porcentaje de ocupación promedio anual en los destinos turísticos de montaña del Corredor de los Lagos

\begin{tabular}{|c|c|c|c|c|c|c|}
\hline & $\begin{array}{l}\text { Cantidad. } \\
\text { plazas } \\
\text { tcas } 2006 \\
\end{array}$ & $\begin{array}{l}\text { Cantidad } \\
\text { plazas tcas } \\
2010 \\
\end{array}$ & $\begin{array}{l}\text { Cant. } \\
\text { plazas } \\
\text { tcas } 2013 \\
\end{array}$ & $\begin{array}{l}\text { Var. \% cant. } \\
\text { plazas } \\
2006 / 2013\end{array}$ & $\begin{array}{l}\% \text { ocup. } \\
\text { plazas tcas } \\
2013^{*}\end{array}$ & $\begin{array}{l}\text { \% ocup. } \\
\text { habitac. } \\
\text { tcas } 2013^{* *}\end{array}$ \\
\hline Aluminé & 197 & 377 & 470 & $138,58 \%$ & $\begin{array}{c}(19,78 \%) \\
25,28 \%\end{array}$ & $\begin{array}{c}(18,33 \%) \\
24,9 \%\end{array}$ \\
\hline Villa Pehuenia & 386 & 731 & 854 & $121,24 \%$ & $36,61 \%$ & $\mathrm{~s} / \mathrm{d}$ \\
\hline $\begin{array}{l}\text { San Martín de los } \\
\text { Andes }\end{array}$ & 6046 & 7214 & 6754 & $11,17 \%$ & $40,83 \%$ & $\begin{array}{c}(36,60 \%) \\
46,99 \%\end{array}$ \\
\hline Junín de los Andes & 624 & 1007 & 1136 & $82,05 \%$ & $24,76 \%$ & $33,37 \%$ \\
\hline Villa La Angostura & 3492 & 4141 & 4133 & $18,35 \%$ & $\begin{array}{c}(41,91 \%) \\
38,12 \%\end{array}$ & $\begin{array}{c}(34,64 \%) \\
44,98 \%\end{array}$ \\
\hline Patagonia de Los Lagos & 11319 & 13803 & 14192 & $25,38 \%$ & & \\
\hline Copahue & 516 & 585 & 645 & $25 \%$ & $\begin{array}{c}(39,66 \%) \\
49,42 \%\end{array}$ & $\begin{array}{c}(33,58 \%) \\
\text { s/d }\end{array}$ \\
\hline Caviahue & 625 & 909 & 977 & $56,32 \%$ & $(31,63 \%)$ & $(25,69 \%)$ \\
\hline
\end{tabular}




\begin{tabular}{|c|c|c|c|c|c|c|}
\hline & & & & & $28,60 \%$ & $35,59 \%$ \\
\hline Patagonia Termal & 1213 & 1293 & $s / d$ & $6,59 \%$ & & \\
\hline
\end{tabular}

La incidencia que tiene la Patagonia de los Lagos, y en particular San Martín de los Andes y Villa La Angostura sobre el volumen de ocupación hotelera provincial -ya que según estadísticas oficiales representan más del $50 \%$ del total de la oferta de alojamiento provincialhacen que la situación que se viene analizando pueda ser extrapolable a la generalidad de la Provincia de Neuquén (ver Tabla $N^{\circ} 7$ ).

Tabla $\mathrm{N}^{\circ} 7$

Síntesis de la evolución cuantitativa de la demanda, la oferta y los porcentajes de ocupación en la Provincia de Neuquén, 2006-2010

\begin{tabular}{|c|c|c|c|c|c|c|c|c|c|c|}
\hline Año & \multicolumn{2}{|c|}{ Cantidad Pernoctes } & \multicolumn{2}{|c|}{$\begin{array}{l}\text { Cantidad } \\
\text { establec. } \\
\text { habilitados }\end{array}$} & \multicolumn{2}{|c|}{$\begin{array}{l}\text { Cantidad } \\
\text { Plazas } \\
\text { habilitadas }\end{array}$} & \multicolumn{2}{|c|}{$\begin{array}{l}\% \text { Ocupación } \\
\text { Plazas }\end{array}$} & \multicolumn{2}{|c|}{$\begin{array}{l}\% \text { Ocupación } \\
\text { habitaciones }\end{array}$} \\
\hline 2006 & 2.228 .958 & Var.\% & 525 & Var.\% & 19537 & Var.\% & 40 & Var.\% & 52,8 & Var.\% \\
\hline 2007 & 2.386 .492 & 7,06 & 588 & 12 & 20965 & 7,31 & 40,25 & 0,63 & 52,1 & $-0,98$ \\
\hline 2008 & 2.310 .400 & $-3,19$ & 640 & 8,84 & 22639 & 7,98 & 36,16 & $-10,17$ & 47,17 & $-9,43$ \\
\hline 2009 & 2.142 .207 & $-7,28$ & 685 & 7,03 & 22672 & 0,14 & 31,55 & $-12,75$ & 38,94 & $-17,45$ \\
\hline 2010 & 2.506 .773 & 17,02 & 724 & 5,69 & 24153 & 6,53 & 35,55 & 12,67 & 44,85 & 15,17 \\
\hline & \multicolumn{2}{|c|}{$\begin{array}{r}\text { Var. \% acumulada } \\
13,59\end{array}$} & \multicolumn{2}{|c|}{$\begin{array}{r}\text { Var. \% } \\
\text { acumulada } \\
33,36\end{array}$} & \multicolumn{2}{|c|}{$\begin{array}{r}\text { Var. \% } \\
\text { acumulada } \\
21,66\end{array}$} & \multicolumn{2}{|c|}{$\begin{array}{r}\text { Var. \% } \\
\text { acumulada } \\
-9,62\end{array}$} & \multicolumn{2}{|c|}{$\begin{array}{r}\text { Var. \% } \\
\text { acumulada } \\
-12,69\end{array}$} \\
\hline
\end{tabular}

Fuente: elaboración propia en base a datos oficiales de la Subsecretaría de Turismo de Neuquén

Aumentan los pernoctes pero ningún porcentaje de ocupación -ni de plazas, ni de habitaciones- evoluciona favorablemente, porque el crecimiento de la oferta llega hasta triplicar el crecimiento de la demanda. Se advierte que para el período 2006-2010, por caso, la cantidad de pernoctes turísticos creció un 13,59\% a escala provincial. Este análisis revela que no está en discusión el desempeño de estos destinos turísticos en lo referente a su atractividad y posicionamiento. Aunque resulta evidente que, tal vez llevados por esa idea de que "todo crecimiento es positivo", no saben o no pueden gestionar su crecimiento, permitiendo estos sobre aumentos de oferta hotelera que atacan la base de competitividad económica de cualquier destino turístico.

\section{El Desarrollo turístico ¿sinónimo de negocio inmobiliario?}

La indagación de las huellas del negocio inmobiliario actuando en la sombra del turismo en Villa La Angostura y San Martín de los Andes permite apreciar dos derivaciones principales. Por un lado, la consideración que buena parte del desarrollo turístico en estos destinos termina asociándose a desarrollo inmobiliario, generando presión sobre los recursos 
comunes, pero invirtiendo el sentido de la competitividad sustentable: la competitividad económica ya no es la del sector turismo, sino la del sector inmobiliario. Por otro, y en buena medida como correlato de lo anterior, la instalación del negocio inmobiliario lleva a una expansión y consolidación de la mancha urbana, usualmente sobre terrenos con alta fragilidad ambiental, en la búsqueda de una privatización del suelo más allá de lo planificado.

La raíz del problema está en la naturaleza de la renta del suelo. Bajo el amparo del dejar hacer del Estado, en la sombra del turismo se forman y nutren círculos viciosos de competencia desmedida e informalidad en el mercado del suelo. El rol medular del Estado y sus instituciones en otorgar carta verde para operaciones inmobiliarias encarece el espacio urbano y afecta la posibilidad de reproducción y supervivencia de las relaciones de producción de estas economías locales. La lógica especulativa, con fecha de vencimiento, promueve destinos caros y aburridos. Si se deja en manos del mercado inmobiliario el crecimiento de los destinos turísticos de montaña -atravesados por procesos de migración de amenidadpermitiendo el libre juego del mercado de la tierra urbana y la comodificación de su patrimonio natural y cultural, el resultado final serán lugares turísticos socialmente excluyentes, espacialmente segregados y ambientalmente insustentables.

La hibridación entre negocio turístico y negocio inmobiliario lleva en definitiva a considerar qué es lo que se entiende por rentabilidad: ¿la rentabilidad turística o la rentabilidad inmobiliaria? ¿Se trata de inversiones que buscan rentabilidad 0 al final termina distorsionándose ese concepto en detrimento de la patrimonialización y de un recupero especulativo sobre bienes raíces? ¿No será que al final todo lo turístico termina siendo rentable, porque todo lo turístico se pone finalmente a la venta?

\section{Referencias bibliográficas}

Appadurai, A. (2008). Modernity at Large: Cultural Dimensions of Globalization. Minneapolis, London: University of Minnesota Press.

Arditi, C.; Carrasco, G.; Martínez, P.; Sepulveda, R. (2003). Gestión de suelo urbano y vivienda social. Elementos para una discusión. Documento de trabajo $\mathrm{N} 1$. Santiago: Universidad de Chile, Facultad de Arquitectura y Urbanismo. Instituto de la Vivienda.

Baer, L. (2012). Mercados de suelo y producción de vivienda en Buenos Aires y su área metropolitana: tendencias recientes de desarrollo urbano y acceso a la ciudad. Revista Iberoamericana de Urbanismo 8, p. 43-58.

Benson, M.; O'Reilly, K. (2009). Migration and the search for a better way of life: a critical exploration of lifestyle migration. The Sociological Review, 57, p. 608-625. 
Bourdieu, P. (2008). Amenity Migration and Post-Tourism - A Geo-Cultural Approach to the Alpine Case. En: Moss, L.A.G., R.S. Glorioso and A. Krause (eds.): Understanding and Managing Amenity-Led Migration in Mountain Regions. - Proceedings of the Mountain Culture at the Banff Centre Conference (pp.25-32). Canadá: Banff.

Castells, M. (2da Ed.) (2000). The information age: economy, society and Culture. Vol. 1. The rise of network society. Oxford, UK.: Blackwell Publishing.

Crouch, G. y Ritchie, B. (2003). The Competitive Destination: a Sustainable Tourism Perspective. London: Cab International.

Gallego, E.; Molins, C. y Dupen, G. (2014). El ciclo de vida de destinos turísticos con Migración de Amenidad y su relación con los problemas de manejo de crecimiento. El caso de San Martín de los Andes, provincia de Neuquén. Ponencia presentada en el VI Congreso Latinoamericano de Investigación Turística. Universidad Nacional del Comahue, Neuquén.

Garay, A. (1996). Crecimiento urbano y consolidación. El caso Buenos Aires. Ejes para la definición de una política de gestión ambiental de infraestructura y servicios urbanos. Buenos Aires: Publicaciones del curso de posgrado GADU. Centro de Investigaciones Ambientales CIAM. Centro Experimental de la Vivienda y el Equipamiento Urbano - CEVEqU.

Glorioso, R. \& Moss, L. (2006). Santa Fe, a fading dream: 1986 profile and 2005 prospect. En: Moss, L. (Ed.). The Amenity Migrants. Seeking and sustaining mountains and their cultures (pp. 73-93).Trowbridge: Cromwell Press.

González, R.; Otero, A.; Lonac, A.; Marioni, S.; Nakayama, L. (2008). Contradictions of Tourism and Amenity Migration Mobilities in Local Development: Four Cases of Study in Argentina. Latin America. En: Moss, Glorioso y Krause (Ed.) (2008). Understanding and Managing Amenity-led Migration in Mountain Regions. Canadá: Banff.

González, R.; Mendieta, M. (2009). Reflexiones sobre la conceptualización de la competitividad de destinos turísticos. Cuadernos de Turismo $N^{\circ} 23$ (pp. 111-128). España: Universidad de Murcia.

González, R., Otero, A., Nakayama, L. Y Marioni, S. (2009). Las movilidades del turismo y las migraciones de amenidad: Problemáticas y contradicciones en el desarrollo de centros turísticos de montaña. Revista de Geografía Norte Grande № 44, Marzo de 2009, pp. 75- 92. Instituto de Geografía, Pontificia Universidad Católica de Chile.

González, R. Otero, A. (2014). Contradictions in amenity-led growth: Insights from the argentine experience. En: Moss, L.; Glorioso, R. (Eds) (2014). Global Amenity Migration. Transforming Rural Culture, Economy and Landscape. The New Ecology Press (pp. 329-342). USA.

González, R. (2011). Los procesos de migración de amenidad y la competitividad de destinos turísticos de montaña del Oeste Canadiense y de la Norpatagonia Argentina. Estudios y Perspectivas en Turismo, 20 (5).

González, R.; Perini, M. M.; Sánchez, L.; Mendieta, M. (2012). El rol del Estado en la competitividad sustentable en destinos turísticos con migración de amenidad. En: Otero y González (Eds.). La Sombra del Turismo. Movilidades y desafíos de los destinos turísticos con migración de amenidad. Neuquén: Educo. 
González, R.; Mantecón, A. (2014). Turismo y negocio inmobiliario: la crisis de un modelo de desarrollo. Tres casos de estudio de Canadá, Argentina y España. Estudios y Perspectivas en Turismo, 23 (4), pp. 685-705.

Huggan, G (2001). The postcolonial exotic. Marketing the margins. New York: Routledge.

Hurstel, S. (2014). Caracterización de la expansión de desarrollos inmobiliarios de tipo residencial y turístico por sobre las áreas de montaña de alta fragilidad ambiental. Caso de estudio San Martín de Los Andes. Tesina de Grado. CEPLADES-Turismo. Facultad de Turismo. Universidad Nacional del Comahue.

Landriscini, G. S. (2008). Dinámica económica y percepción social de los cambios recientes en la localidad fronteriza de Villa La Angostura, Provincia del Neuquén. El impacto en la gestión gubernamental y en el desarrollo local. En: IV Seminario Nacional de la RedMuni I. Articulaciones interinstitucionales para el desarrollo local. Córdoba

McIntyre, N. (2012). Movilidades, Estilos de vida y Mundos Imaginados. En: Otero y González (Eds.). La Sombra del Turismo. Movilidades y desafíos de los destinos con migración de amenidad. Educo: Neuquén.

Merlos, M. (2012). La producción del Espacio en Destinos Post-Turísticos. Caso: Villa La Angostura. Tesina de Grado. CEPLADES-Turismo. Facultad de Turismo. Universidad Nacional del Comahue.

Morales Schechinger, L. (2007). Algunas reflexiones sobre el mercado de suelo urbano. Material del curso "Mercados de Suelo Urbano en América Latina", Lincoln Institute of Land Policy Cambridge, Massachusetts.

Moss, L. (2006). The Amenity Migrants. Seeking and sustaining mountains and their cultures. Trowbridge: Cromwell Press.

Nakayama, L. Y Marioni, S. (2007). Migración por opción: El fenómeno migratorio en destinos turísticos de montaña. IX Jornadas Argentinas de Estudios de Población, Huerta Grande, Córdoba, Argentina.

Otero, A y E. Gallego, E. (2006). El Agua - variable crítica de los umbrales ambientales en destinos turísticos de montaña: El caso de San Martín de Los Andes. Neuquén. Argentina. CEPLADES Turismo. Facultad de Turismo. UNCo. Neuquén.

Otero, A.; González, R. (Eds.) (2012). La sombra del turismo. Movilidades y desafíos de los destinos turísticos con migración de amenidad. Educo: Neuquén.

Otero, A. y González, R. (2014). Más allá de la sombra del turismo. Innovación y cambios territoriales en destinos turísticos de montaña. En: Borsdorf, A., Sánchez, R. et al. (Eds.) (2014). Los riesgos traen oportunidades. Transformaciones globales en los Andes sudamericanos (pp. 227-246). Chile: Instituto de Geografía, Pontificia Universidad Católica de Chile.

Rodríguez, V. (2001). Tourism as a recruiting post for retirement migration. Tourism Geographies, 3 (1), 52-63.

Sánchez, L.; González, R. (2011). Destinos turísticos de montaña con migración de amenidad: Implicancias en el desarrollo turístico local. Caso: Caviahue, Provincia de Neuquén, Argentina. En: Estudios y Perspectivas en Turismo, 20 (2), pp.288-306. 
Sheller, M. \& Urry J. (2004). Places to play, places in play. En: Sheller, M; Urry, J. Tourism Mobilities. Places To Play, Places In Play (pp.1-10). London: Routledge.

Stefanick, L.; González, R. (2012). En busca del paraíso: migración por amenidad y la crisis de crecimiento de los pueblos de montaña del Oeste Canadiense. Estudios y Perspectivas en Turismo, 21 (5).

Subsecretaría de Turismo, Provincia De Neuquén (2010). Oferta de Alojamiento Turístico. Anuario Estadístico en Turismo - Año 2010.

Subsecretaría de Turismo, Provincia De Neuquén (2013). Anuario Estadístico en Turismo - Año 2013.

Urry, J. (1990). The tourist gaze: leisure and travel in contemporary societies. London: Sage Publication.

Urry, J. (2000). Sociology Beyond Societies: Mobilities for the twenty-first century. London: Routledge.

Urry J. (2004). Tourism Mobilities Places To Play, Places In Play. London: Routledge.

Urry, J. (2004). Death in Venice. En: Sheller, M. y Urry, J. Tourism Mobilities Places To Play, Places In Play. London: Routledge.

Urry, J. (2003). Global Complexity. Cambridge: Polity Press. 